\title{
OPTIMIZATION OF WELDING PARAMETERS FOR MIG WELDING
}

\section{OF AL 6061-T6 USING TAGUCHI TECHNIQUE}

\author{
SAMEER S. KULKARNI ${ }^{1} \&$ DR. JAGADEESH P. GANJIGATTI ${ }^{2}$ \\ ${ }^{1}$ Assistant Professor, Department of Mechanical Engineering, \\ B.L.D.E.A's Dr. P G Halakatti College of Engineering \& Technology, Vijayapur, Karnataka, India \\ ${ }_{2}^{2}$ Professor, Industrial Engineering and Management, \\ Siddaganga Institute of Technology, Tumkur, Karnataka, India
}

\begin{abstract}
In present work Metal inert gas welding weld beads are produced of 6mm thick of material Al 6061-T6 aluminum alloy using Taguchi technique as design of experiments for conducting experiments, and influence of MIG welding parameters on weld bead geometries is investigated. The process parameters of welding considered are angle of the gun, Feed rate of electrode wire, Standoff distance, Welding speed and Current. Optimization of welding parameters was obtained by identifying most influencing parameters using $\mathrm{S} / \mathrm{N}$ ratio analysis.
\end{abstract}

KEYWORDS: Al 6061 Alloy, MIG, Taguchi Method \& S/N Ratio

Received: Mar 15, 2019; Accepted: Apr 05, 2019; Published: May 08, 2019; Paper Id.: IJMPERDJUN201977

\section{INTRODUCTION}

In most of the industries like manufacturing, aeronautical, marine industries there are various methods are available to join metals during repairing, production or fabrication process. But still for fabricating works, the welding is one of the commonly used technique because of its convenient, rapid available and economically feasibility. Welding is defined as joining two metals by heating up to melting point and allowing the flow of molten metal of each to undergo integration and solidification process. In this regard it has been concentrated on welding of alloys which can replace applications of mild steel. The aluminum alloys is one of the important alloys which are inhibited in their use of welding applications in aerospace structures because of low strength, fatigue property, fracture resistant. These alloys are undergoing poor solidification, porous microstructure and loss in mechanical properties. These facts make joining of aluminum alloys more limitation in convectional welding methods. In spite of considerable factors of aluminum alloys properties like light weight, high strength to weight ratio, corrosion resistance still welding is limited. But by appropriate utilizing of welding process, to greater extent we can achieve quality weld bead without any poor solidified joints or non porous microstructure. This can be achieved by the MIG welding technique. The arc welding method produces, arc resistance between work piece and electrode in an open atmosphere, which result in impurity, porous weld bead and low strength. These problems can overcome Metal Inert Gas Welding (MIG) developed by the Battle Memorial Institute in 1948.And the most widely used welding technique for aluminum alloys is MIG welding, since it can be adopted for both thick and thin work pieces with deep penetration, with good quality weld bead. 


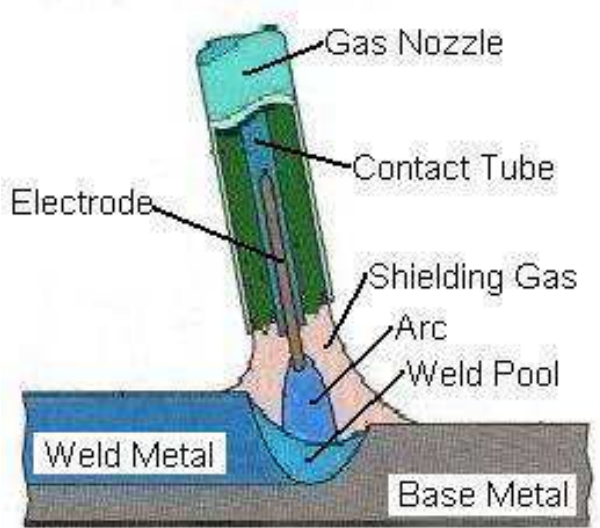

Figure 1: Schematic View of MIG Welding

From the literature survey it was observed that there is effect of welding parameters on output results (1) the rotating electrode wire, voltage and current using pulsed MIG welding on weld bead geometry, reported that there is improvement in weld bead geometry and mechanical properties but however there is a decrease in depth of penetration. The authors also stated that by increasing voltage and current, deposition of electrode wire increases. The others authors focused on weld bead geometrical changes and its shape factor as a result of changes in welding parameters. In their study reported that there is an increase in heat generated which intern increases the depth of penetration until the optimum welding speed and then the heat generated declines, which results in decreasing penetration due to further increase in welding speed. The authors also mentioned that improved shape factor at greater welding speed and heat input. The authors also worked on metal inert gas welding to study the effect of welding parameters on mechanical properties of Al6061 material and reported that increasing inert gas flow rate, pressure along with voltage simultaneously at constant gas pressure (230 bar) resulted in good weld bead and increase in strength of weld bead $(2,3)$. It was also observed from literature survey that welding parameters of $\mathrm{Al} 6061$ on depth of penetration and tensile strength makes changes due to variation in welding current. The author further stated that grain size has a significant effect on material properties. Further, in his work reports that small grain number indicates larger size of grain, and caused loss in mechanical properties, but hardness was increases $(4,5)$.

The other authors they adopted a design of experiment and goal programming methods for the optimization in gas metal arc welding. The main objective of investigation is to study a critical GMAW variable for optimization of properties. It deals with the methodology for study of GMA process with multiple performance objectives utilizing full factorial approach, and result in fact that proposed design of experiments provides more accuracy and increased quality (6). They made an effort to study weld bead geometries produced by gas metal arc welding using artificial neural network using alternating shielding gases. The results showed that the application of alternating shielding gases showed increased in depth of penetration and effective throat thickness of fillet weld while the leg length is reduced, and it also showed that welding speed plays critical role on heat input. The sensitivity analysis also showed that the shielding gas configuration had the lowest influence on the output of the model. The use of alternative shielding gases like argon and $\mathrm{CO}_{2}$ does not shows much difference in the weld bead geometry (7). But from survey it was observed that there is gap in considering all welding parameters of MIG which can influence on weld bead geometries and mechanical properties of weld bead. So to make investigation and to know the effect of each parameters, a design of experiment is considered. 


\section{METHOD}

Design of experiments is a systematic method to establish relationship between input factors and output of the process. In each experiment there are several input parameters which are going to effect on several properties of output and end results. Experimental design also helps in reducing cost of experiment, design changes, material cost and labor complexity. There are several design of experiments are available among them for this study a Taguchi technique was employed to the effect of MIG welding parameters on weld bead geometry of plate. The experiment was performed on Al 6061 -T6 plate of thickness of $6 \mathrm{~mm}$ and size of 100 x 40mm using Al 4043 as a feed wire of diameter $1.2 \mathrm{~mm}$ to make a weld bead by a process of MIG welding. A pure Argon gas is used as a shielding gas at a flow rate of $151 \mathrm{pm}$. To carry out the experiment a DOE called as Taguchi technique was employed by considering 5 welding parameters such as Welding Angle, Feed rate of electrode wire, Standoff distance, Welding speed and Welding current at a two levels. From Taguchi technique by considering 5 factors and 2 levels L32 Orthogonal Array is taken to carry out experiment. The material used for this investigation is $100 \mathrm{~mm}(\mathrm{~L}) \times 50 \mathrm{~mm}(\mathrm{~W})$ x $6 \mathrm{~mm}(\mathrm{~T})$ of $\mathrm{Al} 6061-\mathrm{T} 6$ alloy. The chemical properties of material Al 6061-T6 and filler material $\mathrm{Al} 4043$ is as follows

Table 1: Chemical Composition of Base and filler Materials

\begin{tabular}{|l|c|c|}
\hline \multicolumn{1}{|c|}{ Chemicals } & $\begin{array}{c}\text { Composition of Base } \\
\text { Material in \% (Al 6061) }\end{array}$ & $\begin{array}{c}\text { Composition of Base } \\
\text { Material in \% (Al 4043) }\end{array}$ \\
\hline Manganese(Mn) & 0.083 & 0.05 \\
\hline Iron(Fe) $(\mathrm{Fe})$ & 0.08 \\
\hline Magnesium(Mg) & 0.301 & 0.05 \\
\hline Copper $(\mathrm{Cu})$ & 0.809 & 0.3 \\
\hline Zinc(Zn) & 0.164 & 0.1 \\
\hline Silicon $(\mathrm{Si})$ & 0.044 & 5 \\
\hline Titanium(Ti) & 0.550 & 0.2 \\
\hline Chromium $(\mathrm{Cr})$ & 0.077 & -- \\
\hline Aluminum(Al) & 0.059 & 94.22 \\
\hline
\end{tabular}

During the selecting levels of each parameter a trial run is carried by keeping one parameter in variation and other parameters are kept constant. The working range was determined upon by inspecting the bead for smooth appearance and the absences of any visible defects. The upper limit of a factor was coded as +1 and lower limits as- 1 . The suitable value of selected process parameters for good quality the following are the limits, units and notation are given in below table.

Table 2: MIG Welding Parameters with Minimal and Maximal Values

\begin{tabular}{|c|c|c|c|c|c|}
\hline S. No & $\begin{array}{c}\text { MIG Welding } \\
\text { Parameters }\end{array}$ & Unit & $\begin{array}{c}\text { Upper } \\
\text { Limit }\end{array}$ & $\begin{array}{c}\text { Lower } \\
\text { Limit }\end{array}$ & $\begin{array}{c}\text { Notation for } \\
\text { Parameter }\end{array}$ \\
\hline 01 & Torch angle of Gun & Degree & 90 & 60 & $\mathrm{~A}$ \\
\hline 02 & Wire feed rate & $\mathrm{mm} / \mathrm{min}$ & 55 & 65 & $\mathrm{~W}$ \\
\hline 03 & Standoff distance & $\mathrm{mm}$ & 8 & 12 & $\mathrm{SD}$ \\
\hline 04 & Welding Speed & $\mathrm{mm} / \mathrm{sec}$ & 8.5 & 11.5 & $\mathrm{~S}$ \\
\hline 05 & Welding Current & Amps & 120 & 150 & $\mathrm{I}$ \\
\hline
\end{tabular}




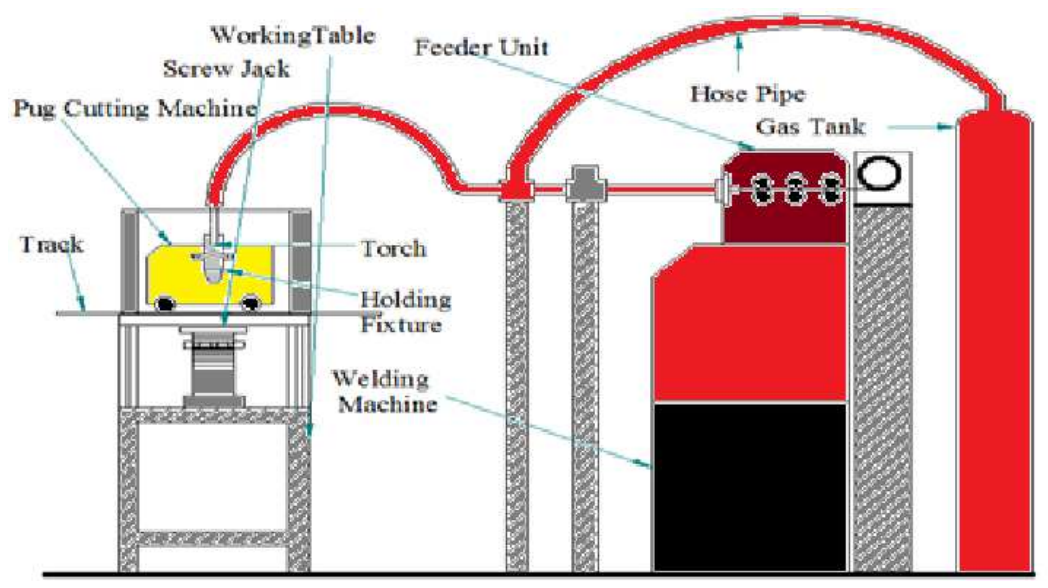

Figure 2: MIG Welding Setup Diagram

To study the effect of welding parameters on output the above mentioned setup was constructed. A schematic diagram of entire setup of MIG welding is shown in Figure 2 consists of a Colton Edura 400 MIG welding Machine, in house fabricated working table with a guiding track is fixed for accurate moment of Pug welding machine to hold the and move the torch at controlled speed, and a welding fixture is made an integral part of the table, welding torch and its accessories, wire feed control unit. A work table holds the work piece to prevent moment during welding. The track fixed on the work table facilitates the movement of Pug welding machine for which a torch is secured at desired angle. The Pug welding machine provides a feature for setting the variable speed for the torch i.e., the welding speed. The screw jack provided below the track on the work table facilitates to vary the standoff distance desired during welding. The welding parameters such as wire feed rate is controlled in wire controller unit and welding current is varied through welding user interface machine.
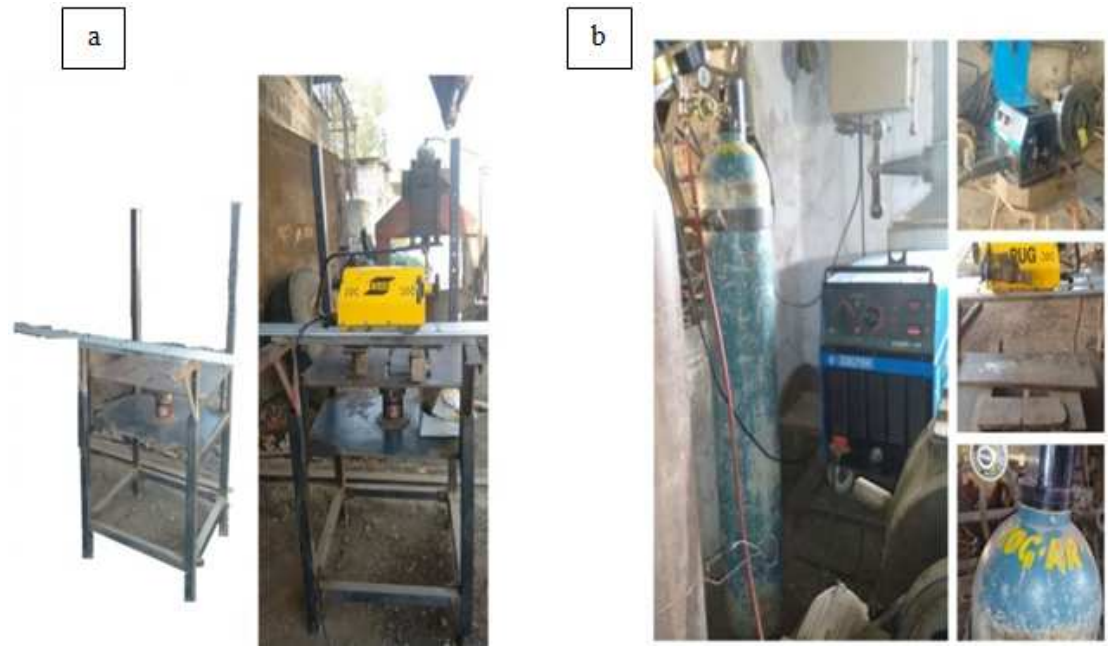

Figure 3: (a) Arrangement of Setup Table Along with Pug Cutting Machine (b) Welding Machine and Shielding Gas Tank Along with Welding Wire Spool

And the results of weld bead geometries is as follows. 
Table 3: Weld Bead Geometries Along with S/N Ratio

\begin{tabular}{|c|c|c|c|c|c|c|c|c|c|c|c|c|c|}
\hline $\begin{array}{l}\text { Sl. } \\
\text { No }\end{array}$ & $\mathbf{A}$ & W & SD & $\mathbf{S}$ & I & $\begin{array}{c}\text { FH } \\
\text { in } \\
\text { mm }\end{array}$ & $\begin{array}{c}\text { S/N } \\
\text { Ratio } \\
\text { for FH }\end{array}$ & $\begin{array}{c}\text { BH } \\
\text { in } \\
\text { mm }\end{array}$ & $\begin{array}{c}\text { S/N } \\
\text { Ratio } \\
\text { for BH }\end{array}$ & $\begin{array}{c}\text { FW } \\
\text { in } \\
\text { mm }\end{array}$ & $\begin{array}{c}\text { S/N } \\
\text { Ratio } \\
\text { for FW }\end{array}$ & $\begin{array}{c}\text { BW } \\
\text { in } \mathbf{m m}\end{array}$ & $\begin{array}{c}\text { S/N } \\
\text { Ratio for } \\
\text { BW }\end{array}$ \\
\hline 1 & 60 & 55 & 8 & 8.5 & 120 & 9.78 & -19.80 & 8.98 & -19.06 & 7.92 & 17.97 & 7.38 & 17.36 \\
\hline 2 & 60 & 55 & 8 & 8.5 & 150 & 8.95 & -19.03 & 8.96 & -19.04 & 8.80 & 18.89 & 8.40 & 18.48 \\
\hline 3 & 60 & 55 & 8 & 11.5 & 120 & 8.93 & -19.01 & 8.71 & -18.80 & 6.58 & 16.36 & 6.66 & 16.46 \\
\hline 4 & 60 & 55 & 8 & 11.5 & 150 & 8.91 & -18.99 & 8.89 & -18.98 & 6.98 & 16.88 & 6.78 & 16.62 \\
\hline 5 & 60 & 55 & 12 & 8.5 & 120 & 9.30 & -19.36 & 8.86 & -18.95 & 7.15 & 17.08 & 7.06 & 16.97 \\
\hline 6 & 60 & 55 & 12 & 8.5 & 150 & 9.17 & $\begin{array}{l}-19.24 \\
\end{array}$ & 9.71 & -19.74 & 8.11 & 18.18 & 7.41 & 17.39 \\
\hline 7 & 60 & 55 & 12 & 11.5 & 120 & 9.47 & -19.52 & 9.41 & $\begin{array}{l}-19.47 \\
\end{array}$ & 5.30 & 14.49 & 5.68 & 15.08 \\
\hline 8 & 60 & 55 & 12 & 11.5 & 150 & 8.90 & -18.98 & 8.71 & -18.80 & 6.89 & 16.77 & 6.15 & 15.77 \\
\hline 9 & 60 & 65 & 8 & 8.5 & 120 & 9.64 & $\begin{array}{l}-19.68 \\
\end{array}$ & 9.75 & $\begin{array}{l}-19.78 \\
\end{array}$ & 7.20 & 17.15 & 7.79 & 17.83 \\
\hline 10 & 60 & 65 & 8 & 8.5 & 150 & 9.06 & -19.14 & 9.59 & -19.63 & 8.90 & 18.99 & 7.59 & 17.60 \\
\hline 11 & 60 & 65 & 8 & 11.5 & 120 & 9.41 & -19.47 & 8.52 & -18.61 & 7.65 & 17.67 & 7.19 & 17.13 \\
\hline 12 & 60 & 65 & 8 & 11.5 & 150 & 9.42 & $\begin{array}{l}-19.48 \\
\end{array}$ & 9.42 & $\begin{array}{l}-19.48 \\
\end{array}$ & 8.22 & 18.30 & 8.20 & 18.27 \\
\hline 13 & 60 & 65 & 12 & 8.5 & 120 & 9.48 & $\begin{array}{l}-19.53 \\
\end{array}$ & 9.20 & -19.27 & 8.96 & 19.04 & 9.21 & 19.28 \\
\hline 14 & 60 & 65 & 12 & 8.5 & 150 & 9.09 & -19.17 & 8.65 & -18.74 & 10.23 & 20.20 & 9.55 & 19.60 \\
\hline 15 & 60 & 65 & 12 & 11.5 & 120 & 8.99 & $\begin{array}{l}-19.08 \\
\end{array}$ & 9.36 & $\begin{array}{l}-19.43 \\
\end{array}$ & 6.90 & 16.78 & 7.51 & 17.51 \\
\hline 16 & 60 & 65 & 12 & 11.5 & 150 & 9.12 & -19.19 & 8.68 & -18.77 & 8.01 & 18.07 & 7.63 & 17.65 \\
\hline 17 & 90 & 55 & 8 & 8.5 & 120 & 9.70 & -19.73 & 9.68 & -19.71 & 7.12 & 17.04 & 8.15 & 18.22 \\
\hline 18 & 90 & 55 & 8 & 8.5 & 150 & 8.91 & $\begin{array}{l}-19.00 \\
\end{array}$ & 9.44 & -19.50 & 8.55 & 18.64 & 9.52 & 19.57 \\
\hline 19 & 90 & 55 & 8 & 11.5 & 120 & 9.84 & -19.86 & 10.05 & -20.04 & 6.40 & 16.12 & 6.35 & 16.05 \\
\hline 20 & 90 & 55 & 8 & 11.5 & 150 & 9.00 & -19.08 & 9.41 & -19.47 & 6.65 & 16.45 & 6.62 & 16.41 \\
\hline 21 & 90 & 55 & 12 & 8.5 & 120 & 9.88 & $\begin{array}{l}-19.89 \\
\end{array}$ & 9.28 & $\begin{array}{l}-19.35 \\
\end{array}$ & 7.19 & 17.13 & 6.71 & 16.53 \\
\hline 22 & 90 & 55 & 12 & 8.5 & 150 & 8.98 & -19.07 & 9.31 & -19.37 & 6.77 & 16.61 & 7.04 & 16.95 \\
\hline 23 & 90 & 55 & 12 & 11.5 & 120 & 9.34 & -19.41 & 9.61 & -19.65 & 6.24 & 15.90 & 6.30 & 15.98 \\
\hline 24 & 90 & 55 & 12 & 11.5 & 150 & 8.49 & -18.58 & 8.80 & $\begin{array}{l}-18.89 \\
\end{array}$ & 6.80 & 16.65 & 7.13 & 17.06 \\
\hline 25 & 90 & 65 & 8 & 8.5 & 120 & 9.25 & $\begin{array}{l}-19.32 \\
\end{array}$ & 9.39 & -19.45 & 9.57 & 19.62 & 10.90 & 20.74 \\
\hline 26 & 90 & 65 & 8 & 8.5 & 150 & 9.75 & -19.78 & 9.27 & -19.34 & 9.34 & 19.41 & 10.01 & 20.00 \\
\hline 27 & 90 & 65 & 8 & 11.5 & 120 & 9.51 & $\begin{array}{l}-19.56 \\
\end{array}$ & 9.26 & $\begin{array}{l}-19.33 \\
\end{array}$ & 7.78 & 17.81 & 7.16 & 17.09 \\
\hline 28 & 90 & 65 & 8 & 11.5 & 150 & 9.13 & \begin{tabular}{|l|}
-19.21 \\
\end{tabular} & 9.59 & $\begin{array}{l}-19.63 \\
\end{array}$ & 7.91 & 17.97 & 8.03 & 18.09 \\
\hline 29 & 90 & 65 & 12 & 8.5 & 120 & 9.05 & -19.13 & 9.66 & -19.69 & 8.11 & 18.18 & 8.75 & 18.84 \\
\hline 30 & 90 & 65 & 12 & 8.5 & 150 & 9.50 & -19.56 & 9.68 & $\begin{array}{l}-19.72 \\
\end{array}$ & 8.68 & 18.77 & 9.74 & 19.77 \\
\hline 31 & 90 & 65 & 12 & 11.5 & 120 & 9.22 & -19.29 & 9.20 & -19.28 & 7.19 & 17.13 & 7.37 & 17.34 \\
\hline 32 & 90 & 65 & 12 & 11.5 & 150 & 9.22 & -19.30 & 9.38 & -19.44 & 7.45 & 17.44 & 7.28 & 17.24 \\
\hline
\end{tabular}

\section{RESULTS}

The main effect plot of S/N ratio based on mean Depth of front height is depicted in Figure 4.

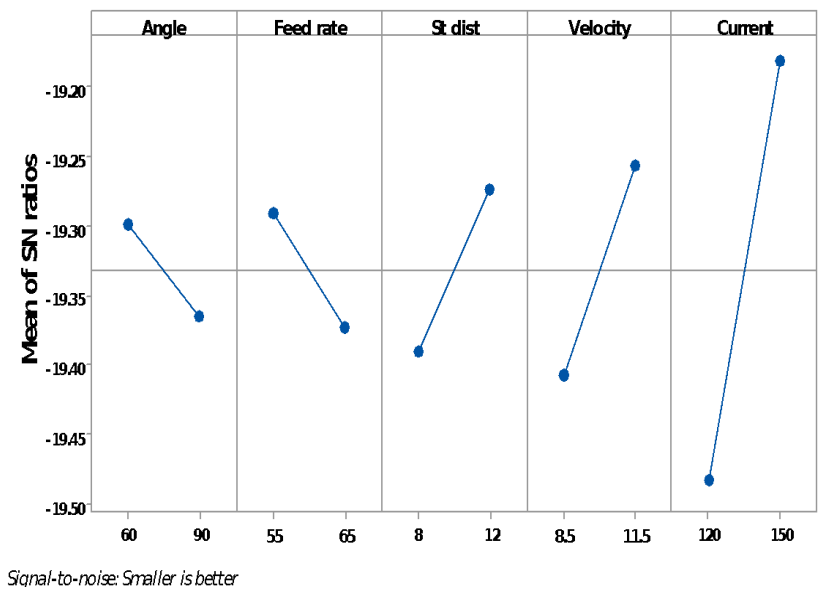

Figure 4: Main Effect Plot of S/N Ratio Based on Data Means of Front Height 
Table 4: Response Table for Signal to Noise Ratio for Front Height

\begin{tabular}{|c|c|c|c|c|c|}
\hline Level & A & W & SD & S & I \\
\hline 1 & -19.30 & -19.29 & -19.39 & -19.41 & -19.48 \\
\hline 2 & -19.37 & -19.37 & -19.27 & -19.26 & -19.48 \\
\hline Delta & 0.07 & 0.08 & 0.12 & 0.15 & 0.30 \\
\hline Rank & 5 & 4 & 3 & 2 & 1 \\
\hline
\end{tabular}

The main effect plot (Figure 4) shows the effect of all welding parameters on S/N ratio of front height of weld bead geometry. The response Table 4 shows that the current has a more significant effect on front height and least significant is on torch angle. In case of torch angle, wire federate, the front height decreases as there level increases, this is due to fact that when angle increases spreading of filler wire increases rather than depositing in narrow manner and even it is same for wire feedrate, whereas in case of standoff distance, welding velocity and current as their level increases, front height also increases. The reason for increases in front height is that as increase in distance produces sufficient gap to buildup of more deposition in narrow region rather than wider, but the increased velocity causes less time to spread filler material in wider direction compared to narrow development. Compared to all parameters a current as significant effect, as current increases more heat is produced which develops increased front height.

The main effect plot of the SN ratio based mean back height is depicted in Figure 5.

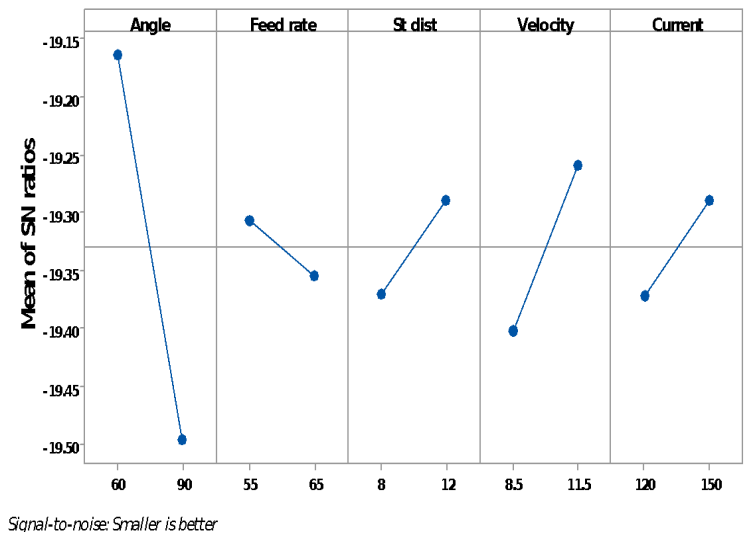

Figure 5: Main Effect Plot of S/N Ratio Based on Data Means of Back Height

Table 5: Response Table for Signal to Noise Ratio for Back Height

\begin{tabular}{|c|c|c|c|c|c|}
\hline Level & A & W & SD & S & I \\
\hline 1 & -19.16 & -19.31 & -19.37 & -19.40 & -19.37 \\
\hline 2 & -19.50 & -19.35 & -19.29 & -19.26 & -19.29 \\
\hline Delta & 0.33 & 0.05 & 0.08 & 0.14 & 0.08 \\
\hline Rank & 1 & 5 & 4 & 2 & 3 \\
\hline
\end{tabular}

The main effect plot for $\mathrm{S} / \mathrm{N}$ ratio based on data mean of back height (Figure 5) shows that a torch angle plays a significant role in decreasing of back height comparing to feed rate as their level increases, where as other welding parameters shows increase in back height as the level increases. The decrease in back height is because of torch angle increases because there is wide deposition of material compared to narrow direction. Increase in back height is due to fact that as standoff distance increases there is sufficient gap for filler material to deposits more on base material, even as velocity and current increases the direction of welding makes more filler material to deposit in narrow area.

The main effect plot of S/N ratio based mean Front width is depicted in Figure 6. 
Table 6: Response Table for Signal to Noise Ratio for Front Width

\begin{tabular}{|c|c|c|c|c|c|}
\hline Level & A & W & SD & S & I \\
\hline 1 & 17.68 & 16.95 & 17.83 & 18.31 & 17.22 \\
\hline 2 & 17.56 & 18.29 & 17.40 & 16.93 & 18.02 \\
\hline Delta & 0.12 & 1.33 & 0.43 & 1.38 & 0.79 \\
\hline Rank & 5 & 2 & 4 & 1 & 3 \\
\hline
\end{tabular}

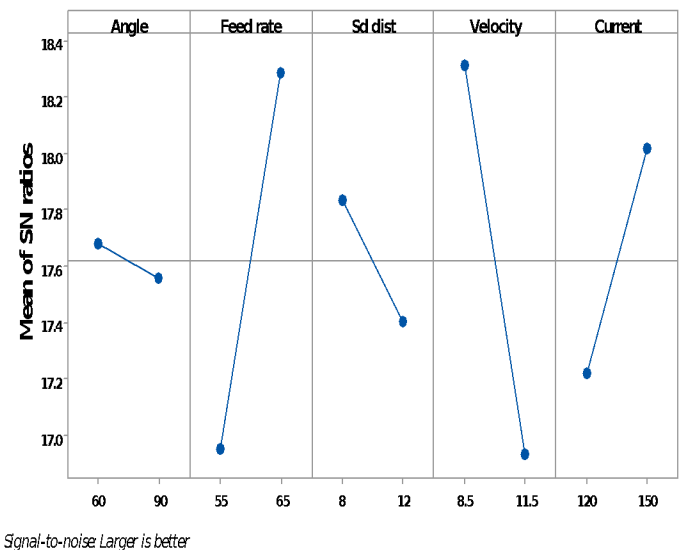

Figure 6: Main Effect Plot of S/N Ratio Based on Data Means of Front Width

It is observed that as torch angle and standoff distance increases in their level, front width of weld bead geometry decreases this due to fact that as standoff distance increases causes less potential difference intern current decreases which causes less heat input and leads to base material less fusion mean while torch angle doesn't have significant effect on front width. In case of feed rate and current front width increases as their level increases the reason that an increase in feed rate causes more filler material to undergo fusion with base material and current leads to maximum heat input. But when welding velocity level increases front width decreases because there is less time to undergo fusion.

The main effect plot of S/N ratio based mean Back width is depicted in Figure 7.

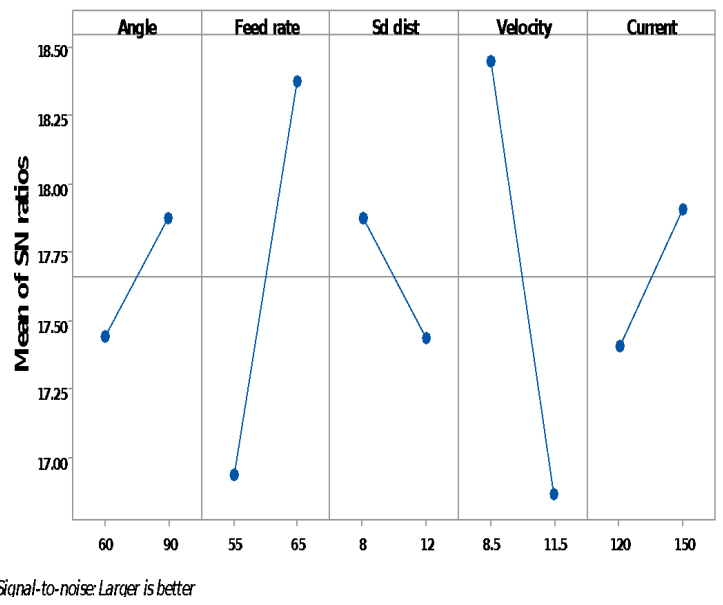

Figure 7: Main Effect Plot of S/N Ratio Based on Data Means of Back Width

Table 7: Response Table for Signal to Noise Ratio for Back Width

\begin{tabular}{|c|c|c|c|c|c|}
\hline Level & A & W & SD & S & I \\
\hline 1 & 17.45 & 16.94 & 17.88 & 18.45 & 17.41 \\
\hline 2 & 17.87 & 18.32 & 17.44 & 16.87 & 17.91 \\
\hline Delta & 0.43 & 1.44 & 0.44 & 1.58 & 0.50 \\
\hline Rank & 5 & 2 & 4 & 1 & 2 \\
\hline
\end{tabular}


In case of torch angle and welding current back width increases as their level increases, due to fact that as increase in current and angle causes sufficient heat input to undergo more fusion. By considering welding velocity it is observed that $\mathrm{S} / \mathrm{N}$ ratio decreases as working level increases, due to reason that as velocity increases there is less time for fusion which decreases in back width. In case of feed rate it is observed that increase in feed rate cause more material to undergo fusion and causes back width to increase. But in case of standoff distance there is a significant decrease in back width since more gap is maintained leads less fusion of material.

\section{CONCLUSIONS}

- In case of torch angle and feed rate as their level increases there is decrease in front height where as in other parameters such as standoff distance, Welding velocity and current front height increases as there level increases. From $\mathrm{S} / \mathrm{N}$ ratio It is found that current is the most significant factor and less effective from torch angle

- The increase in the level of standoff distance, welding velocity and current a back height increases where as torch angle and feed rate increases there is a decrease in back height. And it found to be more effective in case of torch angle and less effective from feed rate of wire.

- As such front width is concerned it gets increases in case of feed rate and current as their level increases. A torch angle as no significant effect on front width. As velocity level and standoff increases there is decrease in front width. From $\mathrm{S} / \mathrm{N}$ ratio it is found that significant effect is from welding velocity and less by torch angle.

- The parameters such as torch angle, feed rate and current as their level get increases their decrease in back width. In case of standoff distance and welding velocity back width decreases. Welding velocity found to be more effective than the other parameters

\section{REFERENCES}

1. D Lingaraju and Narasa Raju "Effect of using a rotating electrode in metal arc weld bead characteristics of Aluminum alloy 6061-T6 weldments" Proceedings of the world congress on Engineering, June 29-July 1 2016, Vol 2,

2. Abbasi. K, Alam. S. Khan. M. J "An experimental study on the effect of increase pressure on MIG welding arc”, International journal of applied engineering research, Dindigul, 2011 Volume 2,No 1,

3. K. Abbasi, S Alam\& Dr. M.I Khan "An experimental study o the effect of MIG welding parameters on the weldbead shape characteristics" IRACST-Engineering science \& Technology; An international journal (ESTIJ),August 2012 Vol. 2,No 4

4. Rai, K. B., \& Dewan, P. R. (2014). Parametric optimization of WEDM using grey relational analysis with Taguchi method. IMPACT: International Journal of Research in Engineering \& Technology, 2, 109-116.

5. Sagar R Chikale, Kishor P Khole, Pawankumar " Prediction of mechanical properties of alloy 6061-T6 by using GMAW" International Journal of current engineering and technology, June 2016 Special issue 5

6. Sagar R Chikale, Kishor P Khole, Pawankumar, Panakajkumar Verma “ A study of Micro structures of Gas Metal arc welded Aluminum alloy 6061-T6” International Journal for innovative Research in Science and Technology, July 2016, Vol 3,Issue 2

7. Kumar, M. N., Venkatesh, S., \& Hussain, M. M. (2017). Experimental investigation on influence of process parameters in selective laser sintering on roundness using Taguchi method. Int. J. of Mechanical and Production Engineering Research and Development, 7, 45-52. 
8. Y. T.IC, F. Elaldi, F. Pakdil, and N. E. Ipek "Design of Experiment and Goal Programming Application for the GMAW Process" April 2012, vol. 91

9. S. W. Campbell, A. M. Galloway, and N. A. Mcpherson "Artificial Neural Network Prediction of Weld Geometry Performed Using GMAW with Alternating Shielding Gases”, Welding research, June 2012, Vol. 91 
